\title{
IDADE DE INÍCIO DA PRÁTICA SISTEMÁTICA E VÍNCULO FEDERATIVO DE JOGADORES PARTICIPANTES DA SUPERLIGA NACIONAL DE VOLEIBOL MASCULINO TEMPORADA 2010/2011
}

\author{
Danilo Augusto Ribeiro, Universidade do Norte do Paraná - UNOPAR, Londrina, Paraná \\ - Brasil \\ Carolina Mendonça Vasconcelos, Universidade Estadual de Londrina - UEL, Londrina, \\ Paraná-Brasil \\ Wilton Carlos de Santana, Universidade Estadual de Londrina - UEL, Londrina, Paraná- \\ Brasil
}

\section{RESUMO}

O objetivo do estudo foi traçar um perfil de iniciação de jogadores participantes da Superliga Nacional de Voleibol 2010/2011. Para tanto, foi utilizada a técnica de observação direta extensiva e a aplicação de um formulário contendo quatro questões. Participaram do estudo 95 jogadores com média de idade de 25,32( $\pm 4,72)$ pertencentes a oito equipes de quatro estados. Para análise dos dados, utilizou-se a contagem, a estatística descritiva percentual, média e desvio padrão. Os resultados apontaram que 85,27\% iniciaram a prática sistemática entre 10 e 12 anos, idade recomendada pela literatura; $69,48 \%$ vincularam-se à federação de seu estado na idade recomendada para iniciar a especialização no voleibol, a partir dos 14 anos e 72,40\% praticou outro esporte de forma sistemática além do voleibol. Conclui-se que ao iniciar a prática sistemática e o vinculo federativo em idades recomendadas pela literatura, os participantes não passaram por um processo de especialização precoce na modalidade, contrapondo a ideia de que para se chegar à categoria principal no esporte coletivo, devem-se especializar precocemente os participantes.

Palavras-Chave: Voleibol; Iniciação; Especialização precoce.

\section{AGE OF ONSET OF THE SYSTEMATIC PRACTICE OF FEDERAL BOND AND PARTICIPATING PLAYERS OF THE NATIONAL VOLLEYBALL LEAGUE SEASON 2010/2011}

\begin{abstract}
The objective of this study was to draw a profile of initiation of participating players of the National Volleyball League 2010/2011. To this end, we used extensive direct observation technique and the application on a form containing four questions. Participated in this study 95 players with an average age of $25.32( \pm 4.72)$ belonging to eight teams from four States. For data analysis, we used the descriptive statistics, the percentage count, mean values and standard deviation. The results showed that $85.27 \%$ started systematic practice between 10 and 12 years, recommended age for literature; $69.48 \%$ linked to their State Federation in the recommended age to start specialisation in volleyball from 14 years and $72.40 \%$ practiced other sports besides volleyball systematically. It is concluded that to start the systematic practice and the Federal link in ages recommended by literature, participants
\end{abstract}


have not gone through a process of early specialization in, opposed the idea that to get to the main category in collective sports, specialize early participants.

Key-Words: Volleyball; Initiation; Early specialization.

\section{EDAD DE INICIO DE LA PRÁCTICA SISTEMÁTICA DE LOS BONOS FEDERALES Y PARTICIPAN JUGADORES DE LA TEMPORADA 2010/2011 DE LA LIGA NACIONAL DE VOLEIBOL}

\section{RESUMEN}

El objetivo de este estudio fue establecer un perfil de iniciación de jugadores participantes del voleibol nacional Liga 2010/2011. Para ello, utilizamos la técnica de observación directa extensiva y la aplicación en un formulario que contiene cuatro preguntas. Participaron en este estudio 95 jugadores con una edad media de 25,32 ( \pm 4.72) pertenecientes a ocho equipos de cuatro Estados. Para análisis de datos, se utilizan la estadística descriptiva, la cuenta del porcentaje, valores promedio y desviación estándar. Los resultados mostraron que $85.27 \%$ comenzó la práctica sistemática entre 10 y 12 años, recomendada la edad para la literatura; $69.48 \%$ vinculado a su Federación de estado en la edad recomendada para iniciar la especialización en voleibol de 14 años y $72.40 \%$ practicado otros deportes además de voleibol sistemáticamente. Se concluye que para iniciar la sistemática práctica y Federal enlazan en edad recomendada por la literatura, los participantes no hayan pasado por un proceso de especialización temprana, se opuso a la idea de que para llegar a la categoría principal en deportes colectivos, se especializan primeros participantes.

Palabras-Clave: Voleibol; Iniciación; Especialización temprana. 


\section{INTRODUÇÃO}

O sucesso internacional do voleibol brasileiro é incontestável, pois a seleção nacional, tanto feminina quanto a masculina, têm conseguido resultados muito expressivos, tornando-se referência de qualidade no voleibol mundial e por conta disso, houve um aumento significativo de alunos procurando escolinhas de voleibol. ${ }^{1}$ Neste sentido, o processo de formação de atletas de voleibol vem sendo realizado de forma que os resultados alcançados ocorram a partir da renovação das equipes adultas, com atletas de ótima qualidade. ${ }^{2}$

Pensando na qualidade da formação dos jogadores, a Confederação Brasileira de Voleibol (CBV) implantou o Viva-Vôlei, que é um projeto de iniciação ao voleibol e tem como objetivo educar e socializar as crianças de 7 a 14 anos por meio do esporte. O processo pedagógico do projeto é baseado na essência lúdica do jogo utilizando-se do "mini-vôlei" com regras adaptadas para cada faixa etária. ${ }^{3}$

Há um consenso na literatura de que, para se trabalhar com qualidade de ensino de esportes na infância, a criança deve vivenciar diferentes modalidades esportivas, propiciando à criança um repertório de movimentos mais amplo e variado, desta forma, desenvolvendo as capacidades coordenativas de cada modalidade praticada. ${ }^{4-8}$

Neste sentido, as "Escolinhas de Voleibol" devem ser substituídas por "Escolas de Esportes”, que produzirão melhores jogadores de voleibol, já que a prática específica em uma única modalidade esportiva na infância limitará as possibilidades de desenvolvimento da criança no processo de ensino-aprendizagem do esporte. ${ }^{4}$ Entende-se que um atleta adulto de voleibol, assim como em outras modalidades, deve ter uma vivência motora na infância muito variada, pois o seu repertório motor tem muita influência sobre às capacidades coordenativas, que são fundamentais na aquisição de habilidades esportivas. ${ }^{4,6}$

A partir de formação diversificada, o sistema nervoso encontra-se na fase principal de desenvolvimento por volta dos 12 anos de idade, sendo que o que não foi adquirido de aspecto coordenativo até então, dificilmente será mais desenvolvido. ${ }^{9}$ Esta é idade recomendada pela literatura para ser especializar em uma modalidade específica. Antes 
disso, ocorrerá o processo de especialização precoce, muito comum em alguns esportes. As crianças que se especializam somente depois de alcançar a puberdade tendem a serem atletas mais consistentes, com menores danos e com um desenvolvimento esportivo pleno ao longo dos anos. ${ }^{7}$

A literatura esportiva aponta que a especialização precoce submete a criança a riscos consideráveis. Por consequência, se adotada no processo de ensino-aprendizagem procedimentos tenham uma alta exigência de treinamento, pode acontecer de as crianças, afastarem-se do esporte, abandonarem a prática, diante da excessiva cobrança de pais, treinadores pelo resultado da competição e da falta de relacionamento entre as partes. ${ }^{10-12}$

Diante disto, este artigo tem como objetivo traçar o perfil de iniciação ao voleibol de jogadores participantes da Superliga Nacional de Voleibol 2010/2011, procurando saber com que idade esses jogadores começaram a prática sistemática do voleibol, com que idade foram federados e se praticaram algum outro esporte antes da prática do voleibol, propiciando assim, reflexões acerca do processo de iniciação de atletas de alto rendimento.

\section{METODOLOGIA}

\section{Técnica de Pesquisa}

Para o levantamento de dados foi utilizada a técnica de observação direta extensiva e a aplicação de um formulário contendo quatro questões. ${ }^{13}$ Optou-se por esse instrumento devido à facilidade para sua aplicação, pois as equipes se encontravam em Londrina (local da investigação) com alguns dias de antecedência e também que os atletas não precisaram dispor de muito tempo para as respostas, pois a pesquisa de campo foi realizada diretamente no local dos treinos.

\section{Participantes}

Participaram do estudo 95 atletas do sexo masculino, com idade média de 25,32 $(4,72)$ anos, pertencentes a oito equipes participantes da Superliga Masculina de Voleibol, temporada 2010/2011 representando os estados de São Paulo, Rio de Janeiro, Minas Gerais e Santa Catariana.

Conexões: revista da Faculdade de Educação Física da UNICAMP, Campinas, v. 11, n. 3, p. 75-85, jul./set. 2013. 


\section{Coleta e análise dos dados}

Os dados foram coletados no Ginásio Moringão e nos Hotéis em que as equipes ficaram hospedadas, todos localizados na cidade de Londrina - PR. O período das entrevistas foi de novembro de 2010 a março de 2011. Após serem previamente informados sobre a proposta do estudo e os procedimentos aos quais seriam submetidos, os participantes assinaram um Termo de Consentimento Livre e Esclarecido.

Para análise dos dados, utilizou-se a contagem, a estatística descritiva percentual, média e desvio padrão.

\section{RESULTADOS E DISCUSSÃO}

Na Tabela 1, apresentam-se os resultados em relação ao início dos sujeitos na prática sistemática do vôlei.

Tabela 1 - Categorias, idade média de início, frequência relativa, número de participantes

\begin{tabular}{llll}
\hline Categorias & Idade média & \% & N \\
\hline Até 10 anos & $13,12 \pm(2,56)$ & 6,31 & 6 \\
Mirim $(10$ e 12) & & 47,37 & 45 \\
Infantil $(13,14$ e 15) & & 37,9 & 36 \\
Infanto-juvenil (17 e 18) & & 7,37 & 7 \\
Adulto & 1,05 & 1 \\
\hline Total & & $\mathbf{1 0 0}$ & $\mathbf{9 5}$ \\
\hline
\end{tabular}

Apesar de uma pequena parte ter se iniciado precocemente e outra pequena parte se iniciado tardiamente, a maior parte dos atletas, $85,27 \%$, teve uma iniciação sistemática no voleibol em idades recomendadas pela literatura, a partir de 10 anos.

A idade adequada para o início do envolvimento específico de forma sistemática com a modalidade se dá por volta dos 10 e 12 anos. ${ }^{14-15}$ Num estudo realizado com 20 jogadoras brasileiras de voleibol, o início da prática sistemática na modalidade ocorreu entre 11 e 13 anos. ${ }^{16}$ Outro estudo apontou que há um consenso quanto a idade de iniciação da prática sistemática do voleibol, que se situa no início da adolescência, por volta dos 13 anos. ${ }^{17}$ No mesmo raciocínio, um estudo realizado encontrou uma idade média de iniciação por volta Conexões: revista da Faculdade de Educação Física da UNICAMP, Campinas, v. 11, n. 3, p. 75-85, jul./set. 2013. ISSN: 1983-9030 
de 11,6 (2,43) anos de idade, e constataram que as jogadoras de maior sucesso se envolveram com o esporte mais tardiamente, e verificando-se que quanto mais alto nível de desempenho, maior foi a idade de início encontrada. Estes mesmos autores afirmam que a idade média de início das atletas de seleção adulta é de 13,2 (1,55) anos, portanto a maioria das atletas de alto rendimento talvez não tenha disputado as categorias pré-mirim e mirim. ${ }^{2}$

Os resultados de todos os estudos citados vão ao encontro dos encontrados no presente estudo.

Afirma ainda o autor que, um atleta adulto de voleibol tem o seu repertório de soluções muito influenciado pela vivência motora que ele teve na infância, e pela intensidade com que foram desenvolvidas, as capacidades coordenativas ocorrem entre os doze anos. ${ }^{9}$ Após essa etapa da vida, pouco se pode fazer para a melhoria delas. Portanto a vivência de outros esportes na infância é fundamental para que a capacidade coordenativa da criança seja desenvolvida.

Na Tabela 2 pode-se ver o resultado com relação ao início do vínculo à uma federação.

Tabela 2 - Categoria, idade média de vínculo federativo, frequência relativa, número de participantes

\begin{tabular}{llll}
\hline Faixa Etária & Idade média & $\mathbf{\%}$ & $\mathbf{N}$ \\
\hline Até 10 anos & $14,5 \pm(2,36)$ & 1,05 & 1 \\
Mirim (10 a 13) & & 29,47 & 28 \\
Infantil (14 a 16) & 49,47 & 47 \\
Infanto-juvenil (17 a 18) & & 16,85 & 16 \\
Adulto & 3,16 & 3 \\
\hline Total & $\mathbf{1 0 0}$ & $\mathbf{9 5}$ \\
\hline
\end{tabular}

No presente estudo observa-se que uma parte dos atletas se federou muito cedo. Mas uma grande parte deles $(69,48 \%)$, vinculou-se à federação do seu estado em idades recomendadas para iniciar o processo competitivo formal no voleibol, que ocorre a partir dos 14 anos. $^{5}$ 
A idade em que há o comprometimento com uma prática sistemática, deixando a ênfase no jogo deliberado e na motivação intrínseca dos primeiros anos, cedendo à motivação orientada para o rendimento, seja somente após os 16 anos. ${ }^{17}$ Quanto mais novas as crianças, maiores serão as necessidades de uma prática lúdica, que permita experiências criativas e prazerosas. ${ }^{18}$ Isto não acontece se forem federadas e começarem a competir desde cedo, pois a cobrança por parte dos pais, técnicos e professores vai existir. ${ }^{10-12,19}$

Quando se aumenta o nível de importância da competição, acaba-se acontecendo fortalecendo os fatores que podem ameaçar a alegria e a saúde psicológica da criança. Portanto, não é recomendado que os atletas sejam federados muito cedo. Devem vivenciar a maior quantidade de esportes possíveis e não passarem pelo estresse competitivo na infância. $^{20}$

$\mathrm{Na}$ Tabela 3 é apresentada a porcentagem de atletas que praticaram outros esportes de forma sistemática.

Tabela 3 - Prática de outro esporte, frequência relativa, número de participantes

\begin{tabular}{cll}
\hline Praticaram outro esporte? & $\mathbf{\%}$ & $\mathbf{N}$ \\
\hline Sim & 72,64 & 69 \\
Não & 27,36 & 26 \\
\hline Total & $\mathbf{1 0 0}$ & $\mathbf{9 5}$
\end{tabular}

A grande maioria dos jogadores entrevistados $(72,64 \%)$ teve uma prática esportiva mais diversificada, praticaram mais que o voleibol de forma sistemática, com treinos semanais. A criança deverá ter uma prática esportiva da forma mais diversificada possível, enfatizando ainda que a especialização precoce não colabora com o alcance de altos níveis de desempenho. ${ }^{2,21}$ Para desenvolver as capacidades coordenativas não se pode praticar uma modalidade sozinha, para garantir um desenvolvimento básico geral das capacidades coordenativas somente a prática de diversas modalidades. ${ }^{9}$ Portanto na infância deve-se adotar uma formação poliesportiva para que corresponda à essas expectativas, a criança deve desenvolver qualidades físicas básicas e deve ter o contato com os fundamentos de diversas modalidades. ${ }^{5}$ 


\section{CONCLUSÃO}

De acordo com os objetivos e os resultados encontrados, conclui-se que apesar de uma pequena parte ter se iniciado precoce ou tardiamente, a maioria se iniciou na idade adequada e recomendada pela literatura, o vínculo à federação também ocorreu na idade ideal, porém ainda tiveram atletas que passaram pelo estresse competitivo precocemente.

Pôde-se observar também que grande parte dos jogadores não praticou somente o voleibol durante a infância.

Conclui-se que ao iniciar a prática sistemática e o vinculo federativo em idades recomendadas pela literatura, os participantes não passaram por um processo de especialização precoce na modalidade, contrapondo a ideia de que para se chegar à categoria principal no esporte coletivo, devem-se especializar precocemente os participantes.

A quantidade de estudos sobre a o perfil de iniciação dos jogadores de voleibol e esportes em geral é muito escassa, portanto recomenda-se que mais pesquisas sejam feitas para que estas possam subsidiar treinadores que forem trabalhar com a iniciação do voleibol.

\section{REFERÊNCIAS}

${ }^{1}$ BENETTI, G.; SCHNEIDER, P.; MEYER, F. Os benefícios do esporte e a importância da Treinabilidade da força muscular de pré-púberes atletas de voleibol. Revista Brasileira de Cineantropometria \& Desempenho Humano, Florianópolis, v. 72, n. 2, p. 87-93, 2005.

${ }^{2}$ BOJIKIAN, J. C. M. et al. Talento esportivo no voleibol feminino do Brasil: maturação e iniciação esportiva. Revista Mackenzie de Educação Física e Esporte, São Paulo, v. 6, n. 3, p.179-187, 2007.

${ }^{3}$ CONDEFEDERAÇÃO BRASILEIRA DE VOLEIBOL (CBV). 2013. Disponível em: www.cbv.com.br. Acesso em: 24 abr. 2013. 
${ }^{4}$ BOJIKIAN, J. C. M. Vôlei vs. vôlei. Revista Mackenzie de Educação Física e Esporte, São Paulo, v.1, n.1, p. 117-124, 2002.

${ }^{5}$ BOMPA, T. O. Diretrizes de treinamento para jovens atletas. In: BOMPA, T. O. Treinamento total para jovens campeões. Barueri: Manole, 2002. p. 1-35.

${ }^{6}$ GRECO, P. J.; BENDA, R. N. Iniciação esportiva universal: da aprendizagem motora ao treinamento técnico. Belo Horizonte: Ed. da UFMG, 1998. v. 1.

${ }^{7}$ OLIVEIRA, V.; PAES, R. R. A Pedagogia do esporte repensando o treinamento técnicotático nos jogos desportivos coletivos. In: PAES, R. R.; BALBINO, H. F. Pedagogia do esporte: contexto e perspectivas. Rio de Janeiro: Guanabara Koogan, 2005.

${ }^{8}$ RAMOS, A. M.; NEVES, R. L. R. A iniciação esportiva e a especialização precoce à luz da teoria da complexidade: notas introdutórias. Pensar a Prática, Goiânia, v. 11, n. 1, p. 1-8, jan./jul. 2008.

${ }^{9}$ WEINECK, J. Treinamento ideal. São Paulo: Manole, 1999.

${ }^{10}$ KORSAKAS, P.; DE ROSE JUNIOR, D. Os encontros e desencontros entre esporte e educação: uma discussão filosófico-pedagógica. Revista Mackenzie de Educação Física e Esporte, São Paulo, v. 1, n. 1, p. 83-93, 2005.

${ }^{11}$ MOLINERO, O. et al.; Reasons for dropout in youth soccer: a comparison with other team sports. Motricidad: european journal of human movement, v. 22, p. 21-30. 2009.

${ }^{12}$ SANTANA, W. C. Uma proposta de subsídios pedagógicos para o futsal na infância. Revista UNOPAR Científica, Londrina, v. 2, n. 1, p. 69-85, dez. 1998.

${ }^{13}$ MARCONI, M.; LAKATOS, E. Fundamentos de metodologia científica. 5. ed. São Paulo: Atlas, 2003.

Conexões: revista da Faculdade de Educação Física da UNICAMP, Campinas, v. 11, n. 3, p. 75-85, jul./set. 2013. ISSN: 1983-9030 
${ }^{14}$ BAKER, J.; COTÊ, J.; ABERNETHY, B. Sport specific training, deliberate practice and the development of expertise in team ball sports. Journal of Applied Sport Psychology, London, v.15, p.12-25, 2003.

${ }^{15}$ FERNANDES, J. J. M. Concepção dos treinadores experts acerca do modelo de formação desportiva do voleibolista português. 2004. Dissertação (Mestrado em Ciências do Desporto) - Faculdade de Ciências do Desporto e de Educação Física, Universidade do Porto, Porto, 2004.

${ }^{16}$ DA MATTA, G. The influence of deliberate practice and social support systems on the development of expert and intermediate women volleyball players in Brazil. 2004. These (Doctorate in Philosophy) - University of South Carolina, Columbia, 2004.

${ }^{17}$ MILISTETD, M. Concepções de treinadores "experts" brasileiros sobre o processo de formação desportiva do jogador de voleibol. Revista Brasileira de Educação Física e Esporte, São Paulo, v. 24, n. 1, p. 79-93, jan./mar. 2010.

${ }^{18}$ KANETA, C. N.; CILLO, E. N. P.; FIGUEIREDO, S. H. Psicossociologia do esporte na adolescência. In: SILVA, L. R. R. Desempenho esportivo: treinamento com crianças e adolescentes. São Paulo: Phorte, 2006. p. 271-299

${ }^{19}$ COELHO, R. W.; COELHO, Y. B. Estudo comparativo entre o nível de estresse de crianças envolvidas em diferentes esportes organizados em atividades físicas competitivas informais. Treinamento Desportivo, Paraná, v. 5, n. 1, p. 27-29, 2000.

${ }^{20}$ BECKER JUNIOR, B. A criança no esporte. In: Manual de psicologia do esporte e exercício. 2. ed. Porto Alegre: Nova Prova, 2008. p. 153-169.

${ }^{21}$ SANTANA, W. C.; RIBEIRO, D. A. Idade de início de atletas de futsal de alto rendimento na prática sistemática e em competições federadas na modalidade. Pensar a Prática, Goiânia, v.13, n. 2, p. 1-17, 2010. 
Recebido em: 05 jun. 2013

Aceito em: 30 ago. 2013

Contato: Danilo Augusto Ribeiro daniloburi@yahoo.com.br 